J. Clin. Chem. Clin. Biochem.

Vol. 27, 1989, pp. $41-47$

(C) 1989 Walter de Gruyter \& Co.

Berlin - New York

\title{
Evaluation of the Automated Haematology Analyser Sysmex M-2000
}

\author{
By D. Pohland
}

Altonaer Kinderkrankenhaus, Hamburg, FRG

(Received December 21, 1987//May 18/October 10, 1988)

Summary: The automated Sysmex M-2000 was evaluated according to the ICSH (International Committee for Standardization in Haematology) protocol. After dilution of packed cells with cell-free plasma, blood cell counts were linear. The overall precision of the measured parameters was good; the CV's ranged between $0.64 \%$ and $2.06 \%$. The carry-over was neglible; platelets showed the biggest carry-over with $0.25 \%$ in the Whole Blood Mode, while red blood cells (RBC) showed a carry-over of $0.55 \%$ in the Prediluted Mode.

300 clinical samples were measured on the Sysmex M-2000 and the Sysmex CC-700 with PL-100, and the results were compared. The coefficients of correlation for white blood cells (WBC), red blood cells (RBC), haemoglobin and haematocrit were $>0.99$; platelets showed an $\mathrm{r}$ of 0.982 . Comparison of the results from the Sysmex M-2000 trimodal leukocyte distribution with a manual 100 cell differentiation showed a close correlation for lymphocytes $(r=0.948)$, and neutrophils $(r=0.931)$. The middle cell fraction corresponding to monocytes, eosinophils and basophils showed a correlation with $\mathrm{r}=0.703$.

Pathological samples showed no interference with the blood count. Leukocyte counts less than $1000 \times 10^{9} / 1$ did not effect the measurement of haemoglobin. During the period of evaluation, no instrument malfunctions occurred.

Because of its precision and reliability, the Sysmex M-2000 is well suited for routine work and stat analysis in medium-sized laboratories.

\section{Introduction}

Automated haematological analysis has undergone an enormous development in recent years. New ideas have contributed to the further development of automated cell counting. Presently, several measuring principles are routinely used in the haematological lab: The electrical resistance method (5), optical methods $(6,7)$ and cytochemical methods $(8,9,10)$. These cell counting techniques are being continuously improved, in order to gain more information about the counted cells. Thus, it is now possible for cell counters to differentiate between several leukocyte populations, although at present no automated cell counter can equal the performance of manual differentiation (11).

Using a special lysing reagent, the Sysmex M-2000 can differentiate leukocytes into three distinct popu- lations, corresponding to lymphocytes, a mixed cell fraction containing monocytes, eosinophils and basophils, and a fraction representing neutrophils (= small, medium and large cell populations respectively). The resulting information yields an effective screening for pathological blood samples, providing important diagnostic information and reducing the number of manual differentiations in the haematological laboratory.

This evaluation was done in accordance with the 'Protocol for Evaluation of Automated Blood Cell Counters' of the International Committee for Standardization in Haematology (ICSH) (1). Since the evaluated analyser was the first of its kind in Europe, a multicentre evaluation was not feasible. This study was held in a 250-bed children's hospital with appr. $35 \%$ prediluted blood samples. 


\section{Materials and Methods}

\section{Description of the evaluated system}

The Sysmex M-2000 analyser is an automated 18-parameter blood cell counter with a trimodal white blood cell distribution and histograms of red blood cells and platelets (for a sample print-out sce fig. 1).

\section{WWHOLE BLDOOD}

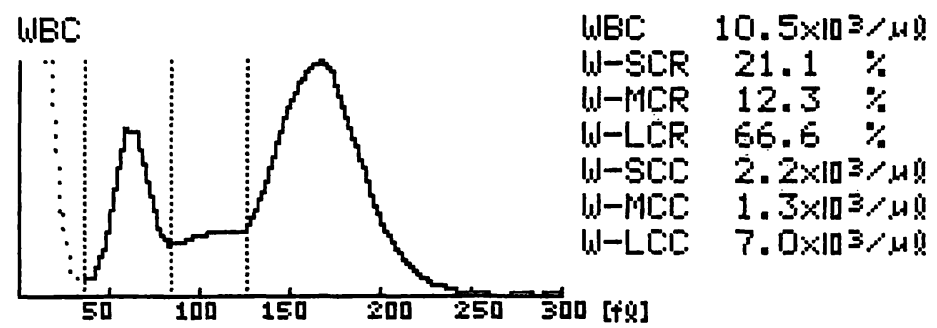

\section{Calibration}

Particle counts are preset by the manufacturer, based on a count volume defined by a reference counter. Haemoglobin was set by the haemoglobin cyanide method using an Eppendorf photometer at $546 \mathrm{~nm}$. The haematocrit was determined by the centrifuged microhaematocrit without correcting for trapped plasma.

\section{Blood samples}

Random specimens from the routine daily workload at the Altonaer Kinderkrankenhaus were used for analysis. These included specimens from patients with various haematological abnormalitites. All samples were collected in EDTA (3). All samples were measured on a Sysmex M-2000 and a Sysmex CC-700 with a PL-100 platelet counter within 2 hours.

\section{Data analysis}

The analysis of the data was carried out according to the ICSH protocol ((1), appendix 1-5). For the study of intra- and interbatch precision measurements, a two-way analysis of variance was used; whereas for estimating the overall reproducibility a one-way analysis of variance was performed. The data of the comparability study were analysed by a paired t-test.

\section{Results \\ Effect of dilution}

Packed cells were diluted with cell-free plasma, to produce 10 samples ranging from $0 \%$ packed cell content to $100 \%$ packed cell content (see figure $2 a-f)$. Each dilution was counted three times. The replicate variance was compared with the variance attributed to the deviation of the dilutions from the regression line using the F-test $(1,4)$ (see table 1 , fig. $2 a-f)$.

Tab. 1. F-test values for dilution measurements

Fig. 1. Sample print-out of the Sysmex M-2000

Print out

PDU 10.5 fo P-LCF 21.0

\begin{tabular}{lrl}
\hline White blood cells & 5.45 & (8 and 20 degrees of freedom) \\
Red blood cells & 11.78 & (8 and 20 degrees of freedom) \\
Haemoglobin & 22.58 & (8 and 20 degrees of freedom) \\
Haematocrit & $15.7 \overline{7}$ & (8 and 20 degrees of freedom) \\
Platelets & 2.01 & (8 and 20 degrees of freedom) \\
\hline
\end{tabular}

WBC:

W-MCR: WBC - middle cell ratio

W-LCR: WBC - large cell ratio

W-SCC: WBC - small cell count

W-MCC: WBC - middle cell count

W-LCC: WBC - large cell count

RBC: $\quad$ Red blood cells

HGB: Haemoglobin

HCT: Haematocrit

MCV: Mean corpuscular volume

\section{Unit}

$10^{3} / \mu 1$

$\%$

$\%$

$\%$

$10^{3} / \mu 1$

$10^{3} / \mu \mathrm{l}$

$10^{3} / \mu 1$

$10^{6} / \mu l$

$\mathrm{g} / \mathrm{dl}$

$\%$

fl

$\mathrm{MCH}$ : Mean corpuscular haemoglobin pg

MCHC: Mean corpuscular haemoglobin $\mathrm{g} / \mathrm{dl}$ concentration

RDW-CV: RBC-distribution width variation \% coefficient

PLT: $\quad$ Platelets

PDW: $\quad$ Platelet distribution width

MPV: $\quad$ Mean platelet volume

P-LCR: Platelet large cell ratio

\section{Precision}

\section{Method used by the manufacturer}

Fresh normal blood was counted consecutively 20 times in the manual mode and the $\mathrm{CV}$ was determined (see tab. 2).

\section{ICSH method}

Intra-batch measurements: 10 samples were tested in triplicate (see tab. 3). 

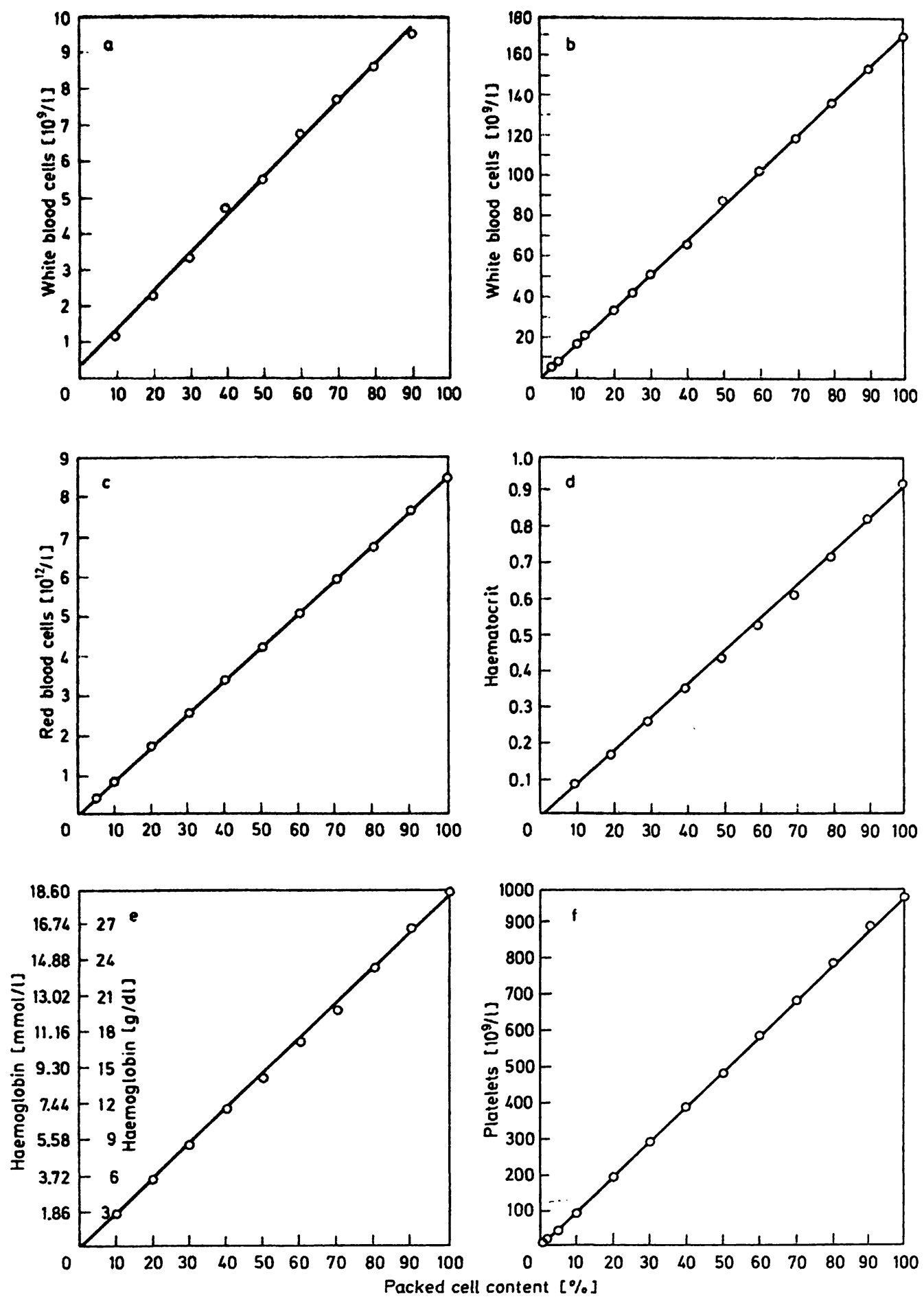

Fig. 2. Linearity studies for white blood cells in the low range 1.2 to $9.6 \times 10^{9} / 1$ (a), white blood cells in the high range 5.7 to $168 \times 10^{9} / 1(\mathrm{~b})$, red blood cells 0.44 to $8.51 \times 10^{12} / 1(\mathrm{c})$, haematocrit 0.089 to $0.921 / 1(\mathrm{~d})$, haemoglobin 3.0 to $30.0 \mathrm{~g} / \mathrm{dl}$ (e) and platelets 15 to $970 \times 10^{9} / 1(f)$.

\section{Overall reproducibility}

Eleven fresh blood samples (as defined in l.c. (1)) with high, normal and low counts were tested randomly, during normal routine, three times over a five hour period (see tab. 4). During this time no drift effects were observed. For day-to-day reproducibility a stabilized blood sample was measured over a period of thirty days (see tạb. 5).

\section{Carry-over assessment}

A high sample (i) was tested three times, followed by a low sample (j) which was also tested three times (see tab. 6). The carry over in \% was calculated according to $1 . c$. (2):

$$
\frac{(j 1-j 3)}{(j 3-j 3)} \times 100 \%
$$


Tab. 2. Precision measured according to the method given by the manufacturer

\begin{tabular}{ll}
\hline & CV \\
\hline White blood cells & $1.49 \%(1.87 \%)^{*}$ \\
Red blood cells & $0.82 \%(0.82 \%)$ \\
Haemoglobin & $0.91 \%(0.42 \%)$ \\
Haematocrit & $0.91 \%(0.94 \%)$ \\
Mean corpuscular volume & $0.27 \%(0.55 \%)$ \\
Mean corpuscular haemoglobin & $0.97 \%(0.69 \%)$ \\
Mean corpuscular haemoglobin & $1.02 \%(0.75 \%)$ \\
$\quad$ concentration & \\
Platelets & $2.73 \%(1.75 \%)$ \\
Mean platelet volume & $1.00 \%(1.23 \%)$ \\
Erythrocyte distribution width & $0.91 \%(1.37 \%)$ \\
Platelet distribution width & $3.51 \%(3.86 \%)$ \\
\hline
\end{tabular}

* ( ) = Prediluted Mode

Tab. 3. Intra- and inter-batch measurements

\begin{tabular}{lll}
\hline & $\begin{array}{l}\text { Intra-batch } \\
\text { CV }\end{array}$ & $\begin{array}{l}\text { Inter-batch } \\
\text { CV }\end{array}$ \\
\hline White blood cells & $1.33 \%$ & $1.35 \%$ \\
Red blood cells & $0.81 \%$ & $0.98 \%$ \\
Haemoglobin & $0.99 \%$ & $0.94 \%$ \\
Haematocrit & $1.49 \%$ & $1.38 \%$ \\
Platelets & $2.79 \%$ & $2.83 \%$ \\
\hline
\end{tabular}

Tab. 4. Overall reproducibility

The coefficient of variation of three measurements within a five hour period was calculated.

\begin{tabular}{ll}
\hline & $\mathrm{CV}$ \\
\hline White blood cells & $0.64 \%$ \\
Red blood cells & $0.67 \%$ \\
Haemoglobin & $0.68 \%$ \\
Haematocrit & $0.92 \%$ \\
Platelets & $2.06 \%$ \\
\hline
\end{tabular}

Tab. 5. Day-to-day reproducibility

\begin{tabular}{|c|c|c|c|c|}
\hline & & $\overline{\mathbf{x}}$ & SD & CV $(\%)$ \\
\hline White blood cells & $\left(10^{9} / 1\right)$ & 7.09 & 0.152 & 2.14 \\
\hline Red blood cells & $\left(10^{12} / 1\right)$ & 4.76 & 0.073 & 1.54 \\
\hline Haemoglobin & $(\mathrm{g} / \mathrm{dl})$ & 15.16 & 0.216 & 1.42 \\
\hline Haematocrit & $(\%)$ & 38.19 & 0.661 & 1.73 \\
\hline Platelets & $\left(10^{9} / 1\right)$ & 223 & 8.76 & 3.94 \\
\hline
\end{tabular}

Tab. 6. Carry-over in \%

\begin{tabular}{lll}
\hline & $\begin{array}{l}\text { Whole } \\
\text { Blood Mode }\end{array}$ & $\begin{array}{l}\text { Prediluted } \\
\text { Mode }\end{array}$ \\
\hline White blood cells & $0.0 \%$ & $0.0 \%$ \\
Red blood cells & $0.0 \%$ & $0.55 \%$ \\
Haemoglobin & $0.0 \%$ & $0.0 \%$ \\
Haematocrit & $0.0 \%$ & $0.41 \%$ \\
Platelets & $0.25 \%$ & $0.37 \%$ \\
\hline
\end{tabular}

\section{Comparability}

300 random samples were analysed consecutively by the Sysmex CC-700, PL-100 and Sysmex M-2000 (see tab. 7, 8).

The individual biases for the tests are illustrated by the residual plots (see fig. $3 \mathrm{a}-\mathrm{f}$ ). For a calculation of the average biases see table 8 .

Interference of high leukocyte counts with haemoglobin measurement

Haemoglobin values for samples with a high leukocyte count were measured both on the Sysmex M= 2000 and using a photometer with a wavelength of $546 \mathrm{~nm}$ (see tab. 9).

Tab. 7. Comparability of two blood cell counters

\begin{tabular}{|c|c|c|c|c|c|c|}
\hline \multirow[t]{2}{*}{ Parameter } & \multirow{2}{*}{$\begin{array}{l}\text { Mean } \\
\text { CC-700 } \\
\text { PL-100 }\end{array}$} & \multirow[t]{2}{*}{$\begin{array}{l}\text { Mean } \\
\text { M-2000 }\end{array}$} & \multirow{2}{*}{$\begin{array}{l}\text { Correlation } \\
\text { coefficient } \\
\mathrm{r}\end{array}$} & \multicolumn{2}{|c|}{$\underline{y}=a+b x$} & \multirow[t]{2}{*}{$t$-value } \\
\hline & & & & a & $\mathrm{b}$ & \\
\hline White blood cells $\left(10^{9} / 1\right)$ & 9.00 & 9.15 & 0.995 & 0.133 & 0.970 & 5.83 \\
\hline Red blood cells $\left(10^{1}=1\right)$ & 4.23 & 4.24 & 0.991 & -0.021 & 1.003 & 1.28 \\
\hline Haemoglobin $(\mathrm{g} / \mathrm{dl})$ & 13.22 & 13.15 & 0.996 & 0.164 & 0.990 & -5.67 \\
\hline Haematocrit $(\%)$ & 40.00 & 40.24 & 0.994 & 0.733 & 0.976 & 3.83 \\
\hline Mean corpuscular ı olume (fl) & 95.1 & 96.9 & 0.993 & -0.268 & 0.849 & 20.63 \\
\hline Platelets $\left(10^{9} / 1\right)$ & 318.0 & 365.0 & 0.982 & 8.035 & 0.849 & 21.27 \\
\hline
\end{tabular}

Tab. 8. Average biases (CC-700/PL-100 to M-2000).

\begin{tabular}{lc}
\hline White blood cells & $+1.66 \%$ \\
Red blood cells & $+0.23 \%$ \\
Haemoglobin & $-0.53 \%$ \\
Haematocrit & $+0.60 \%$ \\
Mean corpuscular volume & $+1.89 \%$ \\
Platelets & $+14.89 \%$ \\
\hline
\end{tabular}

Tab. 9. Comparison of haemoglobin measurements of the Sysmex M-2000 and the reference method

\begin{tabular}{lcc}
\hline $\begin{array}{l}\text { White blood cells } \\
\left(10^{9} / \mathrm{l}\right)\end{array}$ & \multicolumn{2}{c}{ Haemoglobin $(\mathrm{g} / \mathrm{dl})$} \\
\cline { 2 - 3 } & $\mathrm{M}-2000$ & $\begin{array}{l}\text { Reference } \\
\text { method }\end{array}$ \\
\hline 309 & 13.05 & 13.50 \\
478 & 14.25 & 14.87 \\
619 & 6.70 & 6.61 \\
954 & 15.65 & 16.05 \\
\hline
\end{tabular}



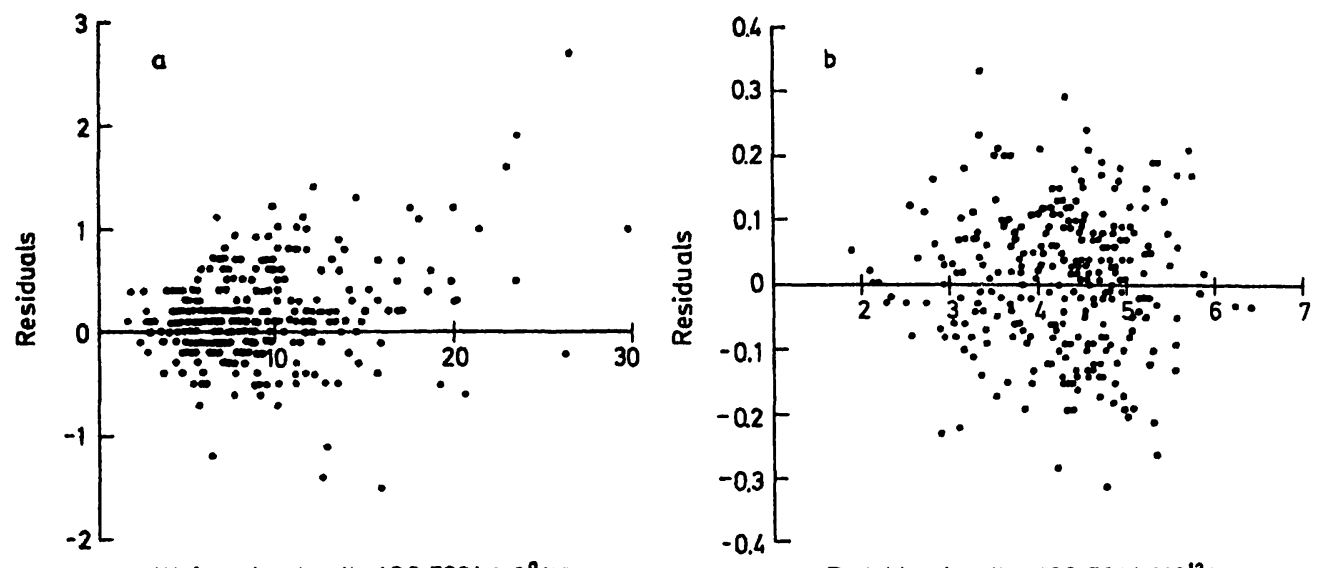

White blood cells (CC 700) $\left[10^{\circ} / 1\right]$

Red blood cells (CC 700) $\left[10^{12 / 1]}\right.$
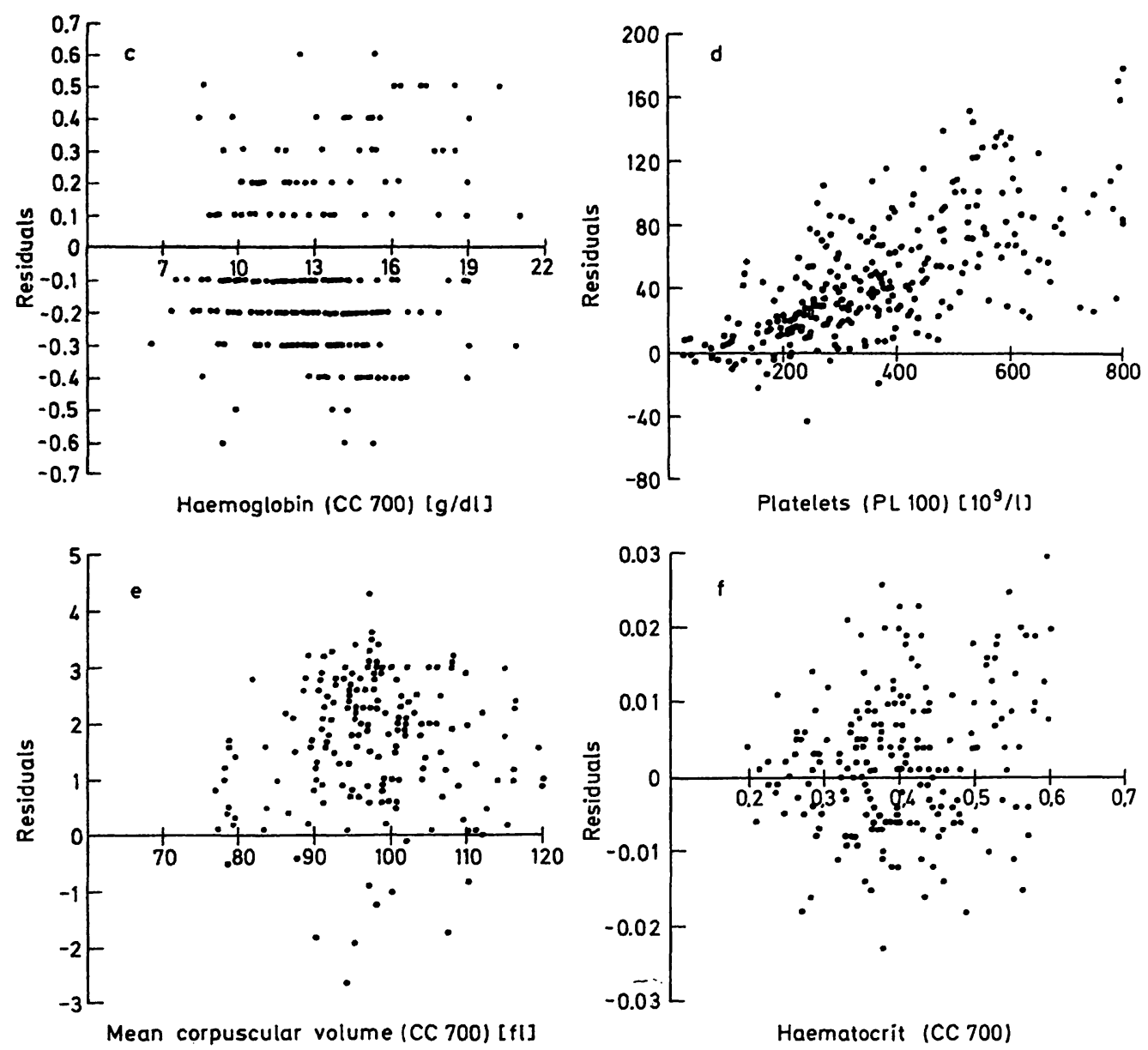

Fig. 3a-f. Residual plot comparing values obtained with the Sysmex CC-700/PL-100 with the Sysmex M-2000.

a) White blood cells;

b) Red blood cells;

c) Haemoglobin;

d) Platelets;

e) Mean corpuscular volume;

f) Haematocrit.

Every point plotted represents a value obtained with the M-2000 minus the corresponding value obtained with the CC-700/PL-100, $n=300$.

\section{Differential leukocyte count}

A preliminary analysis of results obtained by the Sysmex M-2000 and a routine 100-cell manual differential leukocyte count was performed.
The M-2000 leukocyte three part differential corresponds well with lymphocytes (= small cells), monocytes together with basophils and eosinophils (= medium sized cells) and neutrophils (= large cells). The following results were obtained from 300 random samples (see tab. 10, fig. $4 \mathrm{a}-\mathrm{c}$ ). 

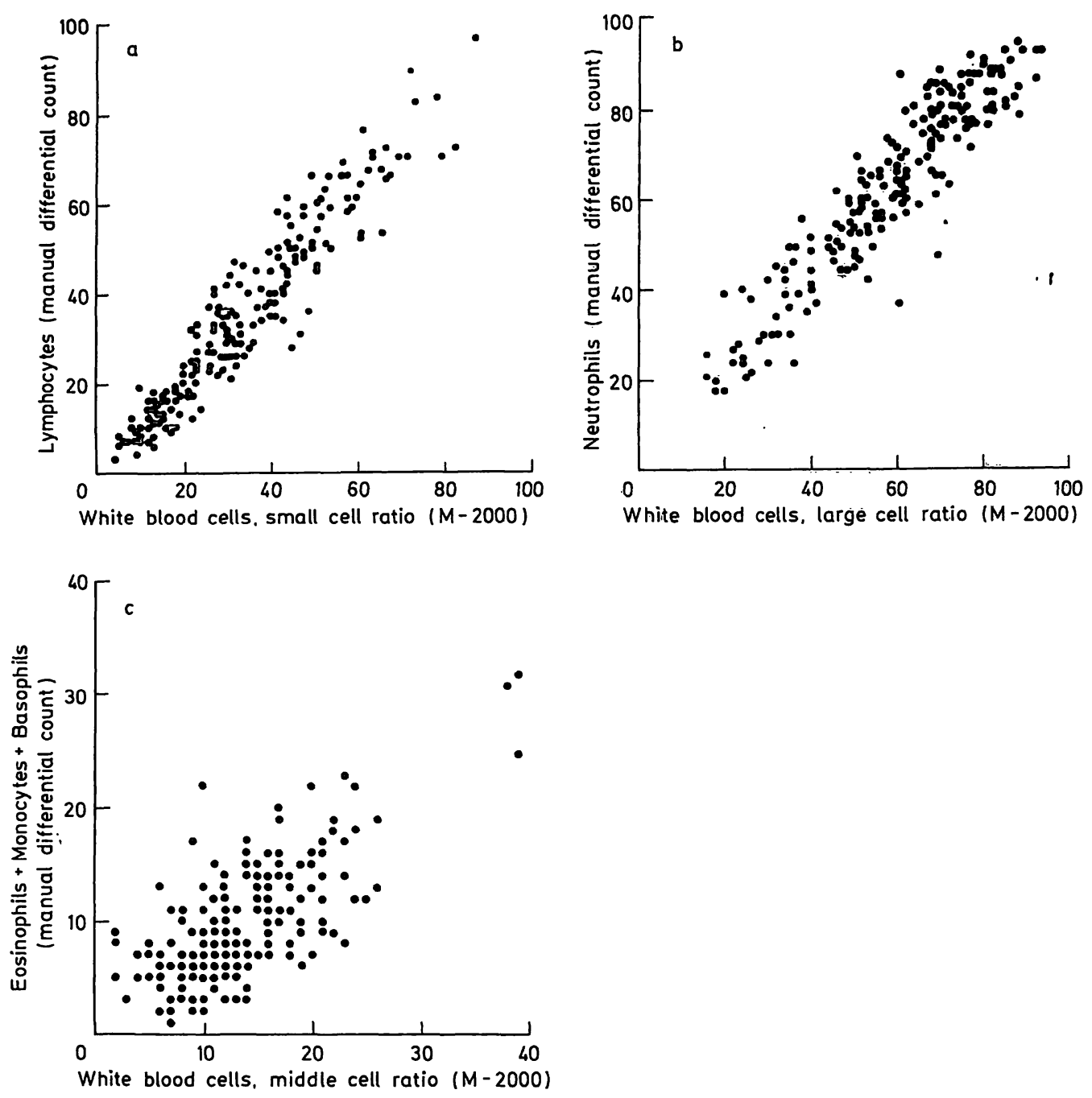

Fig. 4 a-c. Comparison of the 100-cell manual differential with the Sysmex M-2000 trimodal leukocyte cell count, $n=300$.

a) Lymphocytes/small cell ratio

b) Neutrophils/large cell ratio

c) Mononuclears/middle cell ratio

Tab. 10. Assessment of correlation between the manual differential and the Sysmex M-2000

\begin{tabular}{lllllll}
\hline & $\begin{array}{l}\text { Manual } \\
\text { mean } \\
(\%)\end{array}$ & $\begin{array}{l}\text { M-2000 } \\
\text { Mean } \\
(\%)\end{array}$ & $\begin{array}{l}\text { Correlation } \\
\text { coefficient } \\
\mathrm{r}\end{array}$ & $\begin{array}{l}\mathrm{y}=\mathrm{a}+\mathrm{bx} \\
\mathrm{a}\end{array}$ & $\mathrm{b}$ & $\mathrm{t}$-value \\
\hline $\begin{array}{l}\text { Lymphocytes } \\
\text { (W-SCR) }\end{array}$ & 35.8 & 34.6 & 0.948 & -0.458 & 1.046 & -2.48 \\
$\begin{array}{l}\text { Neutrophils } \\
\text { (W-LCR) }\end{array}$ & 60.5 & 58.0 & 0.931 & 4.99 & 0.916 & -4.99 \\
$\begin{array}{l}\text { Monocytes + Basophils + Eosinophils } \\
\text { (W-MCR) }\end{array}$ & 9.4 & 13.2 & 0.703 & 1.30 & 0.609 & 12.25 \\
\hline
\end{tabular}

\section{Discussion}

The Sysmex M-2000 showed good precision and linearity; its carry-over assessment and comparability were excellent. Differences between the Whole Blood Mode and the Prediluted Blood Mode may have been caused by pipetting errors. The high F-test values of the effect of dilution are probably due to pipetting errors which are greater than the variation between replicate measurements at each dilution. Linearity appeared to be excellent when expressed graphically. 
The trimodal differentiation of white blood cells showed a good correlation with the manual 100-cell differential count with regard to lymphocytes and neutrophils. Variations in the mixed cell fraction with regard to monocytes, eosinophils and basophils count may have been caused by the low cell count of these cell types in the manual 100-cell differentiation. Whereas the manual differentiation has its advantages in the classification of cells, the number of cells counted in a modern cell counter gives a better statistical distribution.

As the sample volume in the Prediluted Mode is 20 $\mu l$, pipetting errors may have caused differences between the values obtained in the Whole Blood Mode and in the Prediluted Mode. The measurement of platelets with the PL-100 requires a centrifugation step before counting. The positive bias of the M-2000 with regard to the platelet count may therefore have been caused by a certain loss of platelets due to centrifugation.

\section{References}

1. England, J. M., Rowan, R. M., van Assendelft, O. W., Coulter, W. H., Groner, W., Jones, A. R., Koepke, J. A., Lewis, S. M., Shinton, N. K. \& Thom, R. (1984) Clin. Lab. Haemat. 6, 69-84.

2. Broughton, P. M. G., Gowenlock, A. N., Mc Cormack, J. J. \& Neill, D. W. (1974) Ann. Clin. Biochem. 11, 207.

3. European Committee for Clinical Laboratory Standards (1983) Standard for Specimen Collection, Part 1: Blood Containers. ECCLS Document Vol. 3, No. 1.

4. Sachs, L. (1984) Angewandte Statistik, 6th Edit., SpringerVerlag, Berlin-Heidelberg-New York-Tokio.

5. Coulter, W. H. (1956) Proc. Natl. Electron. Conf. 12, 1034.

6. Tisdall, P. A. (1985) Lab. Med. 16, 228-233.
The presence of paraproteinaemia, uraemia, lipaemia, sickle cell anaemia or bilirubinaemia did not significantly influence the results. Normoblasts were counted in the lymphocyte fraction, causing the automatic discriminator to be set too high.

An extreme leukocytosis may influence the haemoglobin value, but a comparison of the values obtained with the Sysmex M-2000 and with the reference method showed only minor differences for leukocyte counts of up to $954 \times 10^{9} / 1$.

Samples containing cold-agglutinins resulted in an erroneously high leukocyte count with an abnormal distribution curve. Measurement of the sample at $37^{\circ} \mathrm{C}$ corrected this effect.

During the three month evalutation period the Sysmex M-2000 proved to be highly reliable and easy to handle. The data provided by the Sysmex M-2000 was a valuable tool for clinical diagnosis, for more effective screening of pathological samples for manual differentiation, and for the monitoring of therapy.

7. Mohandas, M., Kim, Y. R., Tycko, D. H., Orlik, J. \& Groner, W. (1986) Blood 68, 506-513.

8. Ross, D. W. \& Bentley, S. A. (1986) Arch. Pathol. Lab. Med. 110, 803-808.

9. Pierre, R. V. \& O’Sullivan, M. B. (1974) Mayo Clin. Proc. $49,870-874$.

10. Kaplow, L., Orlowski, L. \& Vazuelis, M. E. (1983) J. Clin. Lab. Automation 3, 167-174.

11. Hohenwallner, W. (1985) Symp. "Linzer Laborrunde", 28. 2. - 1. 3. 85, Bad Gastein.

12. Allen, J. K. \& Batjer, J. D. (1985) Arch. Pathol. Lab. Med. $109,534-537$.

$\begin{array}{ll} & \text { Dr. Dieter Pohland } \\ & \text { Altonaer Kinderkrankenhaus } \\ & \text { Bleickenallee } 38 \\ & \text { D-2000 Hamburg 50 }\end{array}$


